\title{
A EDUCAÇÃO AMBIENTAL E COLETA SELETIVA DE LIXO EM UMA ESCOLA NA CIDADE DE ALEGRE-ES
}

\author{
Elaine Gimenez Guimarães ${ }^{1}$ \\ Keltony de Aquino Ferreira² \\ Sabrina Buqueroni Alves ${ }^{3}$ \\ Luan de Oliveira Cerqueira ${ }^{4}$ \\ Anderson Lopes Peçanha ${ }^{5}$
}

Resumo: O meio ambiente é um dos temas transversais, que visa educar a sociedade para que atue de modo responsável, conservando e preservando os recursos. Esta temática é indispensável para o profissional da educação, sendo assim, no decorrer da disciplina educação ambiental da UFES foi desenvolvida uma dinâmica com discentes do ensino médio de uma escola pública no município de AlegreES, visando mobilizar a coleta seletiva. Os alunos realizaram a separação dos resíduos sólidos em suas residências durante sete dias e após o período proposto os resíduos foram contabilizados e conduzidos ao galpão de triagem da cidade. Posteriormente, aplicou-se o flanelógrafo sobre a separação de resíduos e compostagem, objetivando informar e sanar dúvidas. Desta forma, este trabalho demonstrou que promover a separação do lixo é algo simples, necessitando o envolvimento da sociedade para promover a ação, o que contribui para a conservação dos recursos naturais e a sustentabilidade.

Palavras-chave: Ensino de biologia; Resíduos sólidos; Meio ambiente; Coleta seletiva de lixo.

\footnotetext{
${ }^{1}$ Ciências biológicas Licenciatura/ UFES, Brasil. E-mail: elainegimenezg@hotmail.com.

2 Ciências biológicas Licenciatura/ UFES, Brasil. E-mail: keltony.aquino@yahoo.com.br.

3 Ciências biológicas Licenciatura/ UFES, Brasil. E-mail: sabrinabuqueroni@hotmail.com.

4 Ciências biológicas Licenciatura/ UFES, Brasil. E-mail: luaano@hotmail.com.

5 Professor do Departamento de Biologia/ UFES, Brasil. lopes.pecanha@gmail.com.
} 